\title{
DESIGN OF THE TIME MANAGEMENT SKILLS ACQUISITION SYSTEM USING LEARNING ANALYTICS
}

\author{
Hiroyuki Watanabe ${ }^{1}$, Li Chen ${ }^{2}$, Xuewang Geng ${ }^{2}$, Yoshiko Goda ${ }^{3}$ and Atsushi Shimada ${ }^{4}$ \\ ${ }^{1}$ Faculty of Arts and Science, Kyushu University \\ 744, Motooka, Nishi-ku, Fukuoka 819-0395, Japan \\ ${ }^{2}$ Graduate School of Human-Environment Studies, Kyushu University \\ 744, Motooka, Nishi-ku, Fukuoka 819-0395, Japan \\ ${ }^{3}$ Research Center for Instructional Systems, Kumamoto University \\ 2-39-1, Kurokami, Chuo-ku, Kumamoto, 860-0862, Japan \\ ${ }^{4}$ Faculty of Information Science and Electrical Engineering, Kyushu University \\ 744, Motooka, Nishi-ku, Fukuoka 819-0395, Japan
}

\begin{abstract}
Learning skills include abilities, habits, understanding, and attitudes which are utilized to achieve learning. Students will not achieve good grades unless they properly manage their limited study time. However, it is not easy for them to organize their own study time and learn how to use it efficiently. Notably, learning analytics has not been used in previous research for time management. Learning analytics provides students with accurate data that they can use to manage their study time. Therefore, in this study, we designed a system based on a learning analytics approach with functions that allow students to make their own learning schedules and reflect on their learning behaviors. The system has visualization, calendars, and reflection functions, which are used by both students and their instructors.
\end{abstract}

\section{KEYWORDS}

Learning Analytics, Learning Skills, Learning Analytics Dashboard, Time Management Skills

\section{INTRODUCTION}

Self-regulated learning (SRL) is an important factor in students' learning processes and environment. Zimmerman et al. (1996) refer to self-regulation as the active involvement of learners in their own learning process in metacognition, motivation, and behaviors; accordingly, these are effective perspectives to achieve learning performance and academic goals. Recently, with the advances in information and communications technology, the data of learners' actual learning behaviors can be captured by the learning analytics approach. Yamada et al (2016) and Yamada et al (2018) indicated that SRL awareness have relationships with learning behaviors. Thus, learning analytics is promising approach to investigate the factors of SRL in behavioral level.

In particular, learning data extracted and collected by the learning analytics approach present students' learning behaviors, which can be related to their learning skills. Therefore, it is necessary to identify what basic learning skills can be measured by learning log data that is based on previous research. Learning skills can be divided into three types based on the previous referenced review.

The first is "Information-processing," which includes the competencies associated with acquiring, recording, organizing, synthesizing, remembering, and using information (Hoover and Patton 1995).

The second is "Skills of learning attitudes and habits of learning," which refers to the abilities, habits, understanding, and attitudes that are necessary to achieve the goal of learning (Cottrell 2019). Tanigawa et al. (2014, p.57) described learning skills as "the comprehensive skills needed to learn effectively in higher education institutions, some related to learning skills and others to learning attitudes and habits." Specifically, this refers to time management, taking classes (how to learn to prepare, review, and prepare for exams, how to take lecture notes); reading (how to find literature and the skill of effectively reading it); and writing (summarizing ideas, writing in a clear manner). 
The third type is "Study Strategy," which includes the use of time management and time planning, test anticipation and preparation, and reading and writing strategies as the characteristics of successful students. (Zimmerman et al. 1996).

Gettinger and Seibert (2002) used an information-processing framework to divide learning skills strategies into four categories: (1) repetition- or rehearsal-based skills, (2) procedural study skills, (3) cognitive-based study skills, and (4) metacognitive skills.

Finally, regarding the assessment of basic learning skills, learning skills inventories were mainly used as tools to assess the achievement of learning skills. The Study Skills Inventory was created by Dennis H. Congos of the University of Central Florida; accordingly, it is used by universities, mainly in the United States. It consists of six scales: reading, note-taking, memory, test preparation, concentration, and time management; moreover, there are 51 subscales (Congos 2011).

Although learning skills are classified into different categories, time management is a common element in all categories. The efficient management of learning time is an essential skill for students to implement their learning plans; it is also essential to achieve excellent learning outcomes (Zimmerman 1996).

Thus, time management is regarded as an essential part of learning skills. For example, even if students have prepared and adequately made plans for their work, they will still have difficulties in completing the work as planned without proper time management, since it inhibits their self-efficacy.

Therefore, this study aims to design a learning analytics-based system that helps acquire learning time management skills.

\section{LITERATURE REVIEW}

\subsection{Time Management and Learning Outcomes}

Time management is an essential learning skill for the enhancement of learning performance. Goda et al. (2009) showed that students gradually developed study habits and subsequently felt that having a learning plan is beneficial for their learning. Britton and Tesser (1991) examined their hypothesis that college students' performance was predicted by time management practices. The results showed that time management practices could positively affect college performance (academic performance).

How is time management skill enhanced? Talib and Sansgiry (2012) demonstrated that factors such as time management and test anxiety were significantly related to students' academic performance. Furthermore, Misra and McKean (2000) reported that time management behaviors have a greater buffering effect on academic stress than leisure satisfaction activities. The enhancement of time management is related to the awareness of time. Yamada et al. (2015) indicated that learners who have high timely-awareness, reflected by both negative and positive self-concept about learning, tended to have less procrastination awareness and had high learning performance — but these studies depend on self-report data.

From the insights of the above studies, it is indicated that time management behaviors and practices show positive relationships with students' learning outcomes and positive effects on academic stress. Therefore, it is important to take time management into consideration when teaching and learning.

\subsection{The Relationships between Time Management and Learning Analytics}

The following section presents previous studies that investigated learning time management skills using a learning analytics approach. Many of these studies on time management skills were mainly conducted in educational psychology research - in particular, as a part of self-regulated learning. However, learning analytics, is in fact research that contributes to improving learning and educational environments using various data in not only psychological data but also learning logs. For example, Okubo et al. (2016) investigated effective learning behaviors to predict learning performance using neural networks. Yin et al. (2019) indicated that reading previous pages many times on learning materials promotes learning performance. Shimada et al. (2015) indicated that learning outside of class enhance highly-learning performance, as the perspectives of learning analytics. 
Tabuenca et al. (2014) used mobile devices as tools to facilitate self-regulated learning in online courses and stated and measured the actual time spent in learning over a four-month period. The results show that tracing time can improve time management skills.

Uzir et al. (2020) conducted an exploratory study using data collected in a graduate computer course. It detects time management strategies from actual students' learning activities. The results showed that time management strategies were significantly associated with academic performance. Thus, to measure time management in terms of student behavior, a learning analytics approach could be very useful. Nevertheless, these studies did not specify the processes of acquisition of time management skills.

Schumacher and Ifenthaler (2018) investigated students' expectations of the features of learning analysis systems and their willingness to use these features for learning. The five most commonly accepted learning analysis features by students were: (1) the deadline reminder function; (2) the function of revising learning based on the previous semester outcomes; (3) the function of receiving prompts with self-assessment questions with just-in-time feedback; (4) the function of receiving feedback on assignments created in an online learning environment; and (5) a learning recommendation function for the successful completion of the course.

One of the features of this study is to take the students' perspective (e.g., students' expectations) into consideration. By using the learning analysis functions listed above, the students are expected to monitor their learning during the entire learning process. In particular, it is found that the deadline reminder function is an important function for the students to organize their self-regulated learning and time management activities. These previous studies have shown that the learning analytics approach is effective in measuring time management skills. It was also found that the students themselves wanted to manage their learning activities. Based on the results of the above studies, we designed a system that enables users to manage time to monitor their own learning activities (hereinafter, referred to as the "TM system").

\section{DESIGN}

\subsection{The Design and Function of Visualizing Time Management}

First, this application focuses on visualization and descriptive information such as time spent, access to resources, progress, and comparison to other students in the same class. Therefore, through the implementation of this application, students can understand their own learning, especially in the areas of poor schedule management. In addition, it is expected that knowledge retention will be improved by facilitating the metacognition of time management. The application designed in this study links the data with the BookRoll e-book viewer, the Metaboard dashboard of the learning analytics system, and the displays of the corresponding learning progress of these systems. Figure 1 shows the screen transition of the entire TM system.

\subsection{Application Functions}

The functions of this application are presented in this section and correspond with Table 1. The top screen layout includes graphs, calendars, and schedule lists for quick access. Graphs are visualized with the information of users and classes.

Thus, users can compare their own information with the class information. A schedule list is used to list the contents. Reflection deepens learning content. The calendar also has a reminder function. In addition, instructor-only functions include registration of class information and download of access logs. 


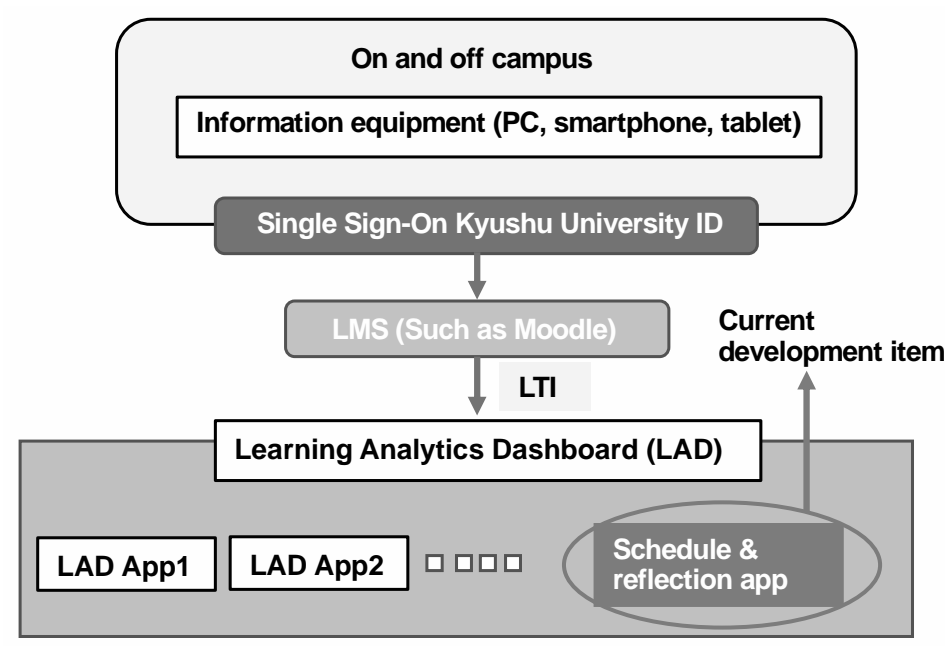

Figure 1. The screen transition of the entire TM system

Table 1. The functions of the TM system

\begin{tabular}{|c|c|}
\hline Function & Description \\
\hline (1)Top Screen Layout & $\begin{array}{l}\text { The top screen layout includes graphs (daily, weekly, and monthly); } \\
\text { calendars (daily, weekly, and monthly); and schedule lists. }\end{array}$ \\
\hline (2) Visualization in graphs & $\begin{array}{l}\text { Users can select a graph (daily, weekly, or monthly) to visualize their } \\
\text { learning behaviors. }\end{array}$ \\
\hline (3) Comparison & Users can compare their behavior with that of the class. \\
\hline (4) Schedule List & The list displays users' plans in date and time order. \\
\hline (5)Reflection & $\begin{array}{l}\text { Reflection function allows users to reflect their learning and make plans } \\
\text { for the next time. They can also refer to their previous reflection contents. }\end{array}$ \\
\hline $\begin{array}{l}\text { (6) Link with learning analytics } \\
\text { dashboard, E-viewer system }\end{array}$ & $\begin{array}{l}\text { Users can check their assignments by linking to the Metaboard learning } \\
\text { analytics dashboard and the BookRoll e-book viewer system. }\end{array}$ \\
\hline (7)Reminder & $\begin{array}{l}\text { E-mails are delivered to help users to learn according to the schedule. } \\
\text { Instructors must register class information (classes, tests, assignment } \\
\text { submissions, etc.) on the calendar. Color the calendar to alert students. }\end{array}$ \\
\hline $\begin{array}{l}\text { (8)Class Information } \\
\text { Registration (Instructors only) }\end{array}$ & $\begin{array}{l}\text { Instructors must register class information (classes, tests, assignment } \\
\text { submissions, etc.) on the calendar. Color the calendar to alert students. }\end{array}$ \\
\hline (9)Download (Instructors only) & $\begin{array}{l}\text { The access log can be obtained from the class information registration } \\
\text { page. }\end{array}$ \\
\hline
\end{tabular}

Concerning the interface of this application, in Figure 2, the graphs on the upper part of the top screen show the learning history (daily, weekly, and monthly). The learning history refers to BookRoll and the Metaboard. The BookRoll system is an e-book viewer, which is used to save digital lecture materials such as slides and notes (Ogata et al. 2015; Ogata et al. 2017). Metaboard is a learning analytics dashboard that aims to provide students with visualized processes and actions based on learning log data from the BookRoll system (Chen et al. 2019; Min et al. 2020). 
The bottom left is the monthly graph screen, and the bottom right is the reflection input screen.

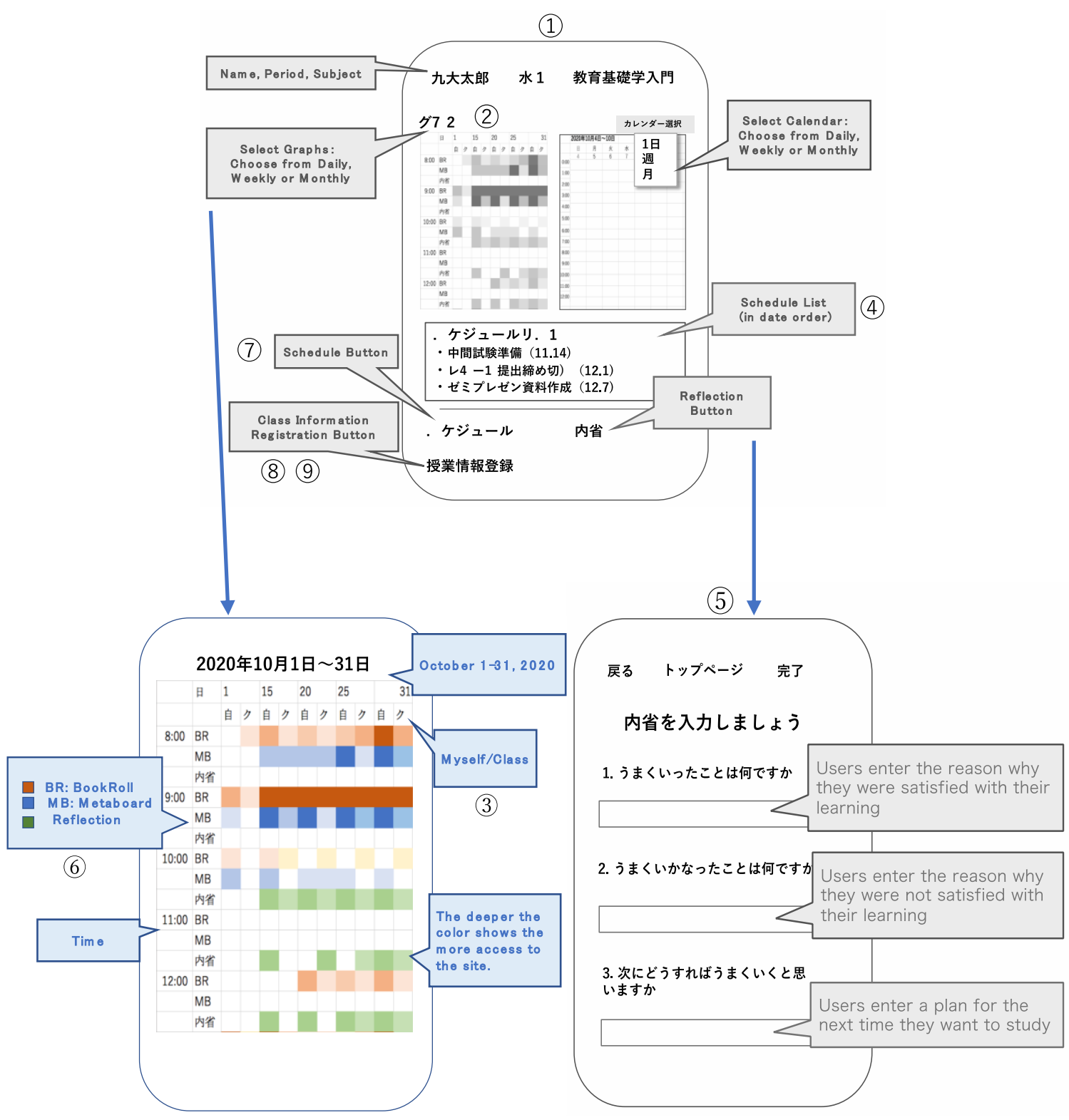

Figure 2. The screen transition of the entire TM system (the numbers in this figure refers to the numbers in Table 1)

\section{CONCLUSIONS AND FUTURE WORK}

In this study, we examined previous research on learning skills, and designed a new application to help students manage their learning time. It is offered to students and teachers. In the design of this application, the functions of graphs, calendars, schedules, and reflections were necessary for time management to aid the monitoring and management of learning plans. We designed a heat map to allow for learning progress comparisons of individual students and classes. In addition, the minimized screen transition is designed to adapt to the use of 
smartphones. We will develop and evaluate the application. In next phase, we will evaluate the effects of the application designed in this study, including the analysis of students' access logs, effectiveness and usability (Motiwalla 2007) through a practical experiment.

\section{ACKNOWLEDGEMENT}

This study was supported by Japan Society for the Promotion of Science(JSPS) [grant number JP19H01716,JP20H01727], and JST AIP [grant number JPMJCR19U1].

\section{REFERENCES}

Britton, B. K. and Tesser, A., 1991. Effects of Time-management Practices on College Grades. Journal of Educational Psychology, 83(3), pp. 405-410.

Chen, $\mathrm{L}$ et al, 2019. Design of Learning Analytics Dashboard Supporting Metacognition. 16th International Conference on Cognition and Exploratory Learning in Digital Age (CELDA 2019), Cagliari, Italy, pp. 175-182.

Congos, D. H., 2011. Starting Out in Community College, McGraw-Hill, Chicago.

Cottrell, S., 2019. The Study Skills Handbook 5th ed. Red Globe Press, London.

Gettinger, M. and Seibert, K., 2002. Contributions of Study Skills to Academic Competence. School Psychology Review, Vol. 31, No. 3, pp. 350-365.

Goda, Y. et al, 2009. Ingenious Attempts to Develop Self-Regulated Learning Strategies with e-Learning: Focusing on Time-Management Skill and Learning Habit. In T. Bastiaens et al (Eds.), Proceedings of World Conference on E-Learning in Corporate, Government, Healthcare, and Higher Education 2009, Chesapeake, VA, USA, pp. 1265-1274.

Hoover, J. J. and Patton, P. R., 1995. Teaching Students with Learning Problems to Use Study Skills: A Teacher's Guide. Austin, TX: Pro-Ed.

Lu, M. et al, 2020. Development of a Learning Dashboard Prototype Supporting Meta-cognition for Students, Companion Proceedings 10th International Conference on Learning Analytics \& Knowledge (LAK20), Frankfurt (online), Germany, pp. 104-106.

Misra, R. and McKean, M., 2000. College Students' Academic Stress and Its Relation to Their Anxiety, Time Management, and Leisure Satisfaction. American Journal of Health Studies, Vol. 16, No. 1, pp. 41-51.

Motiwalla, L. F., 2007. Mobile learning. A framework and evaluation. Computers \& Education, Vol. 49, No. 3, pp. 581-596.

Ogata, H. et al, 2015. E-book-based Learning Analytics in University Education. Proceedings of the 23rd International Conference on Computers in Education (ICCE 2015), pp. 401-406.

Ogata, H. et al, 2017. M2B System: A Digital Learning Platform for Traditional Classrooms in University. 7th International Learning Analytics \& Knowledge Conference (LAK17): Practitioner Track, Vancouver, Canada, pp. 155-162.

Okubo, F., et al, 2016. Learning Activity Features of High Performance Students. Proceedings of the 1st International Workshop on Learning Analytics Across Physical and Digital Spaces (Cross-LAK 2016), pp. 28-33.

Schumacher, C., and Ifenthaler, D., 2018. Features Students Really Expect from Learning Analytics. Computers in Human Behavior, Vol. 78, pp. 397-407.

Shimada, A. et al, 2015. Informal Learning Behavior Analysis Using Action Logs and Slide Features in E-textbooks. Proceedings of IEEE ICALT 2015, pp. 116-117.

Tabuenca et al, 2015. Time Will Tell: The Role of Mobile Learning Analytics in Self-regulated Learning. Computers \& Education, Vol. 89, pp. 53-74.

Talib, N. and Sansgiry, S. S., 2012. Determinants of Academic Performance of University Students. Pakistan Journal of Psychological Research, pp. 265-278.

Tanigawa, H. et al, 2014. Peer Tutor Training. Nakanishiya ed., Kyoto.

Uzir, N.A. et al, 2020. Analytics of Time Management Strategies in a Flipped Classroom, Journal of Computer Assisted Learning, Vol. 36, No. 1, pp. 70-88.

Yamada, M. et al, 2015. The Relationship Among Self-Regulated Learning, Procrastination, And Learning Behaviors In Blended Learning Environment. 12th International Conference on Cognition and Exploratory Learning in Digital Age 2015 (CELDA 2015), pp. 67-74 
Yamada, M. et al, 2016. Learning Analytics in Ubiquitous Learning Environments: Self-Regulated Learning Perspective, The Proceedings of the 24th International Conference on Computers in Education (ICCE 2016), pp. 306-314.

Yamada, M. et al, 2017. Are Learning Logs Related to Procrastination? From the Viewpoint of Self-Regulated Learning. International Conference on Cognition and Exploratory Learning in Digital Age (CELDA 2017), pp. 3-10.

Yamada, M. et al, 2018. BR-Map: Concept map system using e-book logs, International Conference on Cognition and Exploratory Learning in Digital Age 2018 (CELDA 2018), pp. 248-254

Yin, C., et al. , 2019. Exploring the Relationships between Reading Behavior Patterns and Learning Outcomes Based on Log Data from E-books: A Human Factor Approach. International Journal of Human-Computer Interaction, 35(4-5), pp. 313-322.

Zimmerman, B. J. et al, 1996. Developing Self-Regulated Learner: Beyond Achievement to Self-Efficacy. American Psychological Association, Washington DC, USA. 